\title{
GIS-Based Planning and Modeling for Renewable Energy: Challenges and Future Research Avenues
}

\section{Bernd Resch ${ }^{1,2, *}$, Günther Sagl ${ }^{1}$, Tobias Törnros ${ }^{1}$, Andreas Bachmaier ${ }^{3}$, Jan-Bleicke Eggers ${ }^{3}$, Sebastian Herkel ${ }^{3}$, Sattaya Narmsara ${ }^{3}$ and Hartmut Gündra ${ }^{4}$}

1 Institute of Geography-GIScience, Heidelberg University, Berliner Strasse 48, 69120 Heidelberg, Germany; E-Mails: guenther.sagl@geog.uni-heidelberg.de (G.S.); tobias.toernros@geog.uni-heidelberg.de (T.T.)

2 Center for Geographic Analysis, Harvard University, 1737 Cambridge Street, Cambridge, MA 02138, USA

3 Fraunhofer Institute for Solar Energy Systems (ISE), Heidenhofstrasse 2, 79110 Freiburg, Germany; E-Mails: andreas.bachmaier@ise.fraunhofer.de (A.B.);

jan-bleicke.eggers@ise.fraunhofer.de (J.-B.E.); sebastian.herkel@ise.fraunhofer.de (S.H.); sattaya.narmsara@ise.fraunhofer.de (S.N.)

4 geomer GmbH, Im Breitspiel 11b, 69126 Heidelberg, Germany; E-Mail: hg@geomer.de

* Author to whom correspondence should be addressed;

E-Mail: bernd.resch@geog.uni-heidleberg.de; Tel.: +49-6221-54-5573; Fax: +49-6221-54-4529.

Received: 4 March 2014; in revised form: 24 April 2014 / Accepted: 25 April 2014 /

Published: 9 May 2014

\begin{abstract}
In the face of the broad political call for an "energy turnaround", we are currently witnessing three essential trends with regard to energy infrastructure planning, energy generation and storage: from planned production towards fluctuating production on the basis of renewable energy sources, from centralized generation towards decentralized generation and from expensive energy carriers towards cost-free energy carriers. These changes necessitate considerable modifications of the energy infrastructure. Even though most of these modifications are inherently motivated by geospatial questions and challenges, the integration of energy system models and Geographic Information Systems (GIS) is still in its infancy. This paper analyzes the shortcomings of previous approaches in using GIS in renewable energy-related projects, extracts distinct challenges from these previous efforts and, finally, defines a set of core future research avenues for GIS-based energy infrastructure planning with a focus on the use of renewable energy. These future
\end{abstract}


research avenues comprise the availability base data and their "geospatial awareness", the development of a generic and unified data model, the usage of volunteered geographic information (VGI) and crowdsourced data in analysis processes, the integration of 3D building models and 3D data analysis, the incorporation of network topologies into GIS, the harmonization of the heterogeneous views on aggregation issues in the fields of energy and GIS, fine-grained energy demand estimation from freely-available data sources, decentralized storage facility planning, the investigation of GIS-based public participation mechanisms, the transition from purely structural to operational planning, data privacy aspects and, finally, the development of a new dynamic power market design.

Keywords: integration of GIS and energy system models; GIS and renewable energy; GIS-based energy infrastructure planning; future research challenges; fluctuating renewables; structural planning of local energy systems; operation optimization

\section{Introduction}

In the face of the broad political call for an "energy turnaround", we are currently witnessing three essential trends with regard to energy infrastructure planning, renewable energy generation and storage: from planned production towards fluctuating production on the basis of renewable energy sources, from centralized generation towards decentralized generation and from expensive energy carriers towards cost-free renewable energy carriers [1]. The modifications of the energy infrastructure, necessitated by this increasing renewable energy use, require an extension of power and heat networks and the construction of additional power plants and storage facilities [2].

Even though Geographic Information Systems (GIS) are meanwhile slowly penetrating renewable energy research in highly specific and small-scale efforts and their potential for contributing geospatial analysis and visualization methods for awareness-building and decision support has been demonstrated in a number of projects, a broad integration of GIS and energy system models is still missing.

This is particularly surprising, as the value of using GIS-based approaches for solving questions in the energy domain have been proven in a number of research projects, including renewable energy potential assessment [3-7], energy consumption modeling [8-10], planning specific energy infrastructure projects [11-13], building energy demand estimation [14-16], site planning for renewable energy power plants [17-19] or visual impact assessment [20-23]. Although the above-mentioned approaches are promising and highly suitable for dedicated singular applications, no generic methods for trans-domain integration of energy (system) models and geospatial analysis processes have been defined yet.

This is also true for the European Commission Technology Platform's vision paper on Electricity Networks of the Future [24]. One of the key conclusions mentioned in the paper is: "To meet the challenges from new sources of energy, distribution companies may act: (i) at the customer's side, using new technologies and opportunities made available from Demand Side Management and Automatic Meter Management systems; and (ii) at the generator's side, giving the opportunity to remote control and regulate active and reactive power flows to the grid." This statement shows that 
energy system planning and optimization is oftentimes tackled from a purely technical point of view, still neglecting geospatial understanding (e.g., [25]), i.e., the consideration of geographic phenomena, data, correlations and processes.

From a more general point of view, integrating GIS and energy system modeling enables the generation of a more complete picture of the overall energy system and future "energy landscapes" [26]. We claim that it is not enough to consider space and time as additional parameters, but in fact, space and time need to be fully integrated into energy system modeling processes in order to better understand the spatio-temporal dynamics of, for instance, energy demand, availability and the effectiveness of conventional and renewable resources, capacity and load patterns of energy infrastructures, including decentralized energy storages, and, finally, the return of investments and economic profitability.

This paper analyzes the shortcomings of previous approaches in using GIS in renewable energy-related models and planning efforts, extracts distinct challenges from these previous approaches and, finally, defines a set of core future research avenues for GIS-based energy modeling and planning with a focus on the use of renewable energy. The contents of this paper stem from an extensive literature review combined with the authors' experiences in a variety of national and international research projects on the usage of GIS in the field of renewable energy. It shall be noted that the outlook presented in this paper does not focus on a particular spatial scale, but on methods and research needs in the field of integrating energy system models with GIS.

The article does not focus on a methodological review of energy infrastructure planning efforts, on the evaluation of technical solutions, like smart grids or smart metering, the perennial question of how to integrate line networks into energy system models (instead of assuming an omnipresent "copper plate") and the raising of awareness of an integrated system model for coupled heat and electricity transport. Furthermore, the article does not present methodological findings from dedicated research projects, but pinpoints pending research issues.

The structure of this paper is as follows: This introduction is followed by a section on related work in the areas of GIS-based and non-GIS-based approaches to renewable energy modeling and infrastructure planning. Section 3 presents the challenges extracted from the shortcomings of related and previous approaches. Thereafter, Section 4 discusses the future research avenues that we distilled based on those challenges, previous research projects and practical project experiences. Finally, Section 5 wraps up the paper with a short conclusion.

\section{State of the Art}

This section analyzes previous research efforts in the area of renewable energy system modeling and planning with a focus on non-GIS-based approaches (Subsection 2.1) and GIS-based approaches (Subsection 2.2). This subsection is the basis for the definition of challenges and future research avenues laid out in Sections 3 and 4.

\subsection{Non-GIS-Based Approaches (Non-Geospatial Methods)}

Energy system modeling is a common method for optimizing the operational strategy for generating heat and electricity. Over the last few decades, various methods have been developed for simulating 
the distribution of energy in a time-dependent manner [27]. These methods are based on mathematical models, and various optimization algorithms are applied [28,29] to investigate the optimal distributed energy system, considering electricity, heat and gas as energy carriers [30]. All these methods have proven highly useful for planning the overall energy system on a national and international basis. Furthermore, decades ago, most central power plants covered the energy demand of the regions they served, whereas nowadays, the energy distribution is increasingly becoming a spatial question. The rising share of renewable energy sources based on fluctuating yields from wind and solar energy is a geospatial challenge, requiring an improved geospatial understanding of electricity and heat generation.

Modeling of energy demand, mainly buildings' demands, can be done by simplified or detailed, yet complex approaches. Simplified approaches comprise statistical data analysis, e.g., the estimation of a building's entire space heating demand [31]. Detailed approaches tend to model energy systems within a simulation environment. These approaches result in highly accurate output, but require substantial preceding work. Communities or districts are often modeled as 3D objects considering energy and radiation calculation [32].

Energy system modeling requires a variety of input data sources and parameters in order solve optimization problems in a quasi-realistic way. For each task, energy consumption, distribution and generation need to be calculated using different methods and input data from different sources. Building data include networks (like district heating networks as topological data), mostly in building information management (BIM)-like information. Furthermore, datasets of energy related units provide information about specific technical constrains. Most energy system models access and manage this variety of information in database-like applications [33]. Thus, the optimization process can be done by transferring heterogeneous data input into a common format, which provides the possibility of translating a logical problem into a mathematical equation [34].

Baños et al. [35] provide a comprehensive review on optimization algorithms for design, planning and control problems in the field of renewable and sustainable energy. In their methodology review, the authors focus on the discontinuity of renewable energy generation, due to its dependence on the climate. Although several parameters implicitly comprise geospatial data attributes, such as the "location" of wind farms and "neighboring" locations, geographic methods for investigating geographic patterns, such as the spatio-temporal development of energy fluctuations, are not considered. Furthermore, the problem of such energy fluctuations caused by varying renewable energy generation and flexible network operation within hybrid energy systems is comprehensively discussed in terms of economic aspects, specifically the dynamic cost of integrating renewable energy into the power grid [36,37]. "From accommodating ever increasing levels of renewable penetration", the authors conclude that the "direct integration of variable renewable generation poses fundamental technical challenges, because of its high variability, unpredictability and non-dispatchability", but the geospatial dimension of such energy fluctuations is neglected.

The typical technically motivated way of tackling the problem of high variability in energy, both heat and power, fluctuation is the use of suitable energy storages at appropriate locations [38]. As shown in Figure 1, energy storages will be integral components in next generation renewable energy systems [39]. In addition to the fluctuations of renewable energy sources, the impact of human-induced phenomena, such as the demand for mobility on energy fluctuations, can potentially lead to an increasing instability of energy supply. Since mobility is, in fact, a geospatial phenomenon that 
typically comprises a high degree of variability in both space and time, the inter-linkage of GIS with energy system modeling and sustainable energy infrastructure planning becomes self-evident.

Figure 1. Third generation renewable energy system framework (adapted from [39]). CHP, combined heat and power.

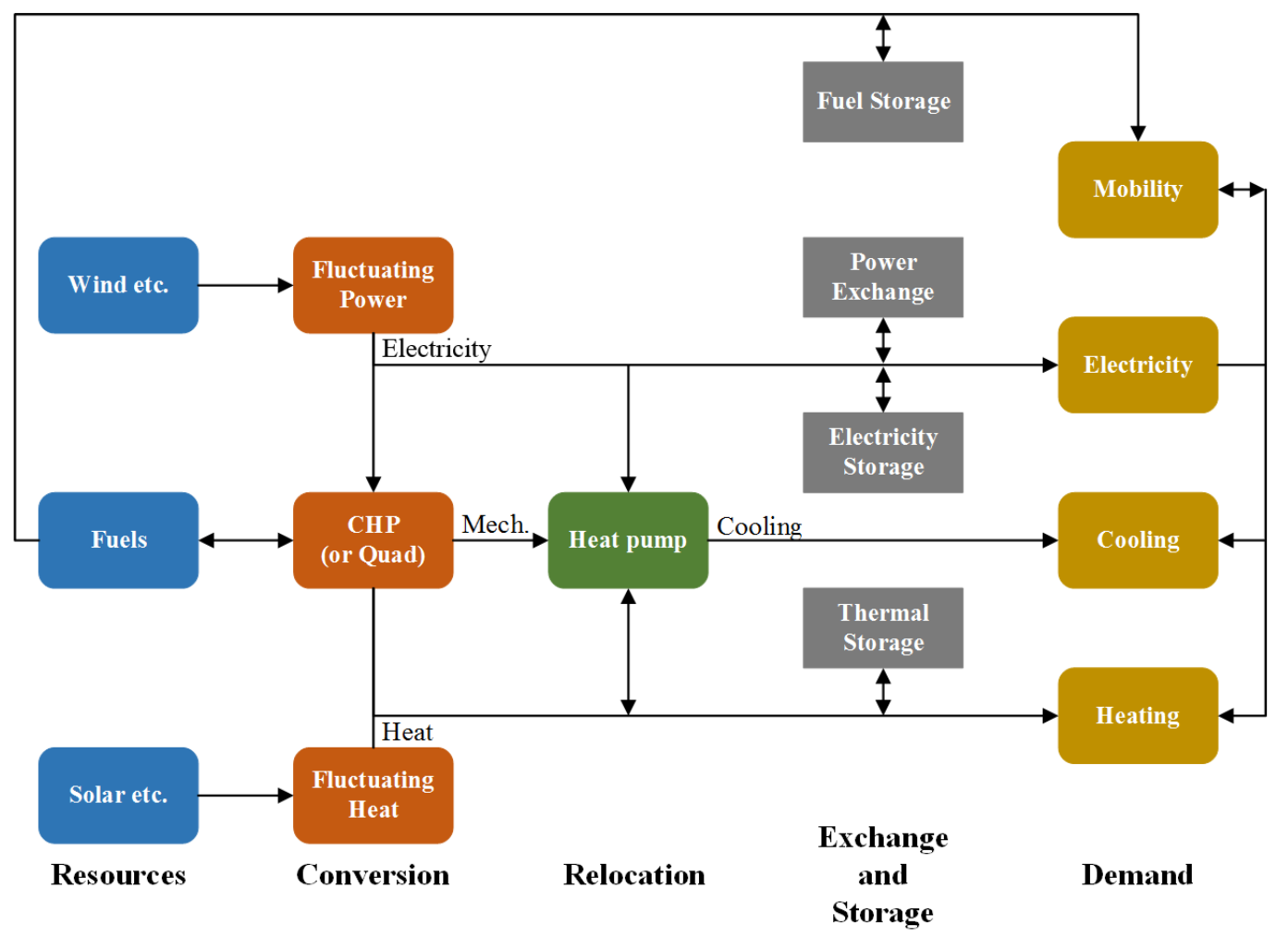

Following [39], heat is linked with domestic hot water consumption (see Figure 1), which is therefore strongly variable depending on the geographical (demographic and topographic) context. Hot water consumption further depends on people's habits, the time of the year, the building type, the building usage and also on the inhabitants' specific lifestyle, etc. [40]. However, such dependencies can vary spatially, as well as temporally, or they tend to cluster in space and time. Surprisingly, a review on the "optimal planning of distributed generation systems in distribution systems" [41], as well as a review on "multi-objective planning of distributed energy resources" [42] do not explicitly identify any geospatial aspects in the impact of distributed generation in distributed networks. In sum, although space and time are indirectly considered in the examples discussed above, more integrated solutions are needed to fully incorporate spatio-temporal dynamics into energy system models and energy network information in order to enable more sustainable energy infrastructure planning in consideration of a growing mix of participating energy producers and energy consumers.

Finally, the issue of planning and implementing the Smart Grid concept has been in the focus of previous research initiatives. Chesi et al. state that "in the future, power grid operators may require a prescribed exchange profile for customers and producers, leading to a diffusion of storage systems or prime movers (especially small combined heat and power for distributed resources), able to balance renewable sources' fluctuations [43]. In this latter case, one of the major issues is the efficient use of the heat co-generated, necessitating the adoption of thermal storages." Even though the authors have identified the need for planning decentralized energy storage distribution, they completely neglect the 
geospatial dimension. This is particularly surprising, as they mention that "the goal that has to be reached is the balancing of renewable sources fluctuations, which may be one of the main issues of the future power grids, constituting a fundamental step towards the development of the Smart Grid", which is an inherently geospatial problem.

\subsection{GIS-Based Approaches (Implicitly Geospatial Methods)}

There are numerous examples where GIS has been used to support the planning process of renewable energy infrastructure. Especially, the identification of suitable places for wind and solar farms, pump storage hydroelectricity [44-46], as well as the mapping of renewable energy resources, including solar photovoltaic, wind, geothermal, biomass and hydro-electricity [11,47-51], have lately been widely explored. These studies employ geospatial data on land use, elevation, buildings and infrastructure. Thus, this research would hardly be practicable without using GIS.

Most of the studies tend to address the potential energy supply without considering the demand. Although highly informative, such an analysis requires more data and more advanced analysis methods. For instance, Kucuksari et al. propose a framework that incorporates GIS, mathematical optimization and simulation in order to find the optimal size and the optimal location of photovoltaic plants for campus environments [52]. The GIS module serves for identifying appropriate rooftops and their photovoltaic panel capacity. However, this approach is purely based on static geodata (in this case, light detection and ranging (LiDAR) data) and does not account for dynamic geographical variables, such as weather conditions, in general, or solar radiation and wind, in particular, as shown in Figure 2. Yet, this approach could be the basis for a more comprehensive framework that also integrates additional spatially varying renewable sources, such as wind or geothermal energy.

Other examples are related to heat network planning. In regions where the potential for expanding district heating $(\mathrm{DH})$ networks diverges in different areas, the economic costs of heat production, transmission and distribution are difficult to estimate. Therefore, taking the geographic component into account using geospatial methods and GIS is a critical part in finding the boundaries to which such an expansion is economically feasible [53]. Although not mentioned by the authors, the most efficient use of energy storage technology, in this case, heat energy storages, also depends on spatial parameters, such as the distance to the next block or to individual houses. The optimal use of energy storages in heat production, heat transmission and heat distribution may significantly influence the overall costs of supply areas. The authors conclude that "heat supply decisions should be based on the spatial placement of the heat demands and the characteristics of the local DH area", which implicitly underpins the integral necessity of GIS. Moreover, the consideration of geospatial aspects in regional energy system optimization is particularly relevant for correctly determining the supply area if the focus is on grid-connected technologies, as in the case of district heating [54]. It can be concluded from such studies that, among geospatial and geometric parameters, the topological parameters, such as connectivity or adjacency of a grid-connected energy infrastructure, constitute vital information for both effective planning and operative tasks. 
Figure 2. Example of a GIS-based energy system modeling workflow for identifying the optimal sites of photovoltaic plants (adapted from [52]).

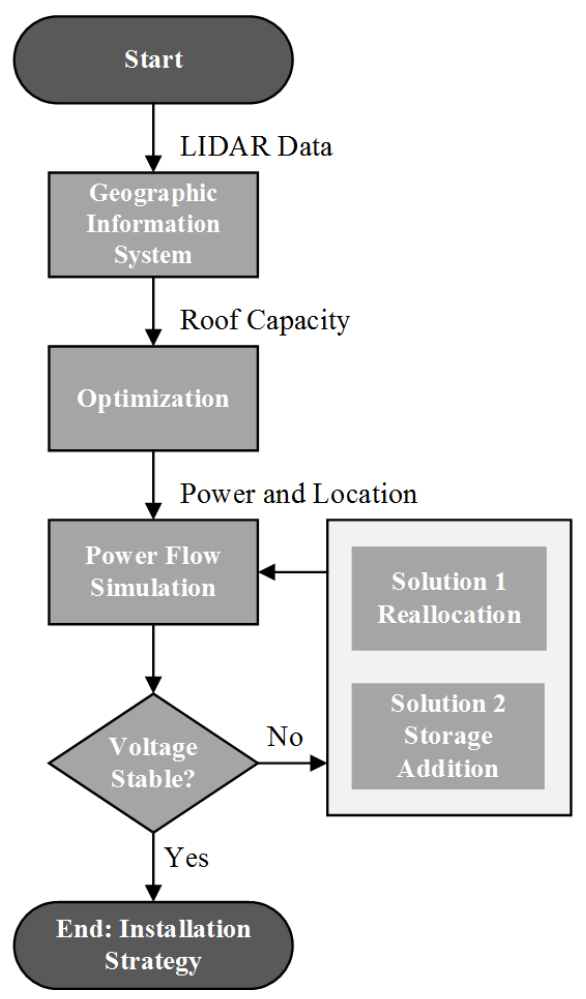

Aydin et al. introduce a methodology based on GIS, fuzzy set theory and multi-criteria decision making for finding the optimal placement of a hybrid wind-solar-photovoltaic (PV) renewable energy system, which can potentially reduce the need for energy storage [44]. Their main argument is that, depending on weather and climate conditions, one renewable energy source is complementing the other. In other words, weaknesses and strengths of the respective systems compensate for each other. However, this methodology may only be applicable if enough space for power plants is available, which is hardly the case, for instance, in densely built-up urban environments. An additional limiting factor is that parcel or building owners can decide individually if and how to use renewable energy. Thus, the individual use of renewable energy sources is oftentimes predetermined in that possible locations for setting up renewable energy power plants are rare in dense urban areas. In a similar way, Omitaomu et al. describe an adapted GIS-based multi-criteria decision analysis approach to determine the suitability for new power generating sites [55]. The methodology considers environmental, geological and socio-economic aspects, amongst others. Although this GIS-based approach is designed to work at large scales, it is spatially explicit in that it divides the entire area of the USA into millions of $100 \mathrm{~m}$ by $100 \mathrm{~m}$ cells and computes the suitability of each cell for new power generation sites. Significant drawbacks of approaches like [44,55] include the lack of ability to consider more dynamic spatio-temporal aspects across different spatial and temporal scales, or the lacking integrability of topological aspects of the underlying energy network as regards the balancing of extraordinary peaks in energy load shifts across spatially explicit cells.

The EnerGEO project aims to provide a versatile modeling platform that will enable planners, environmentalists and governments to calculate, forecast and monitor the environmental impact of changes in the energy mix on local, regional and global scales" [56]. Even though EnerGEO seems to 
be a thorough approach to integrating GIS and energy system models, clear and exploitable results are still missing.

Coupling GIS with energy system modeling is also applied in the field of hydrogen supply, demands and infrastructures. The authors of [57] present an example of such an approach that is anchored within an economy-wide energy systems model of the U.K. For the German hydrogen economy, Ball et al. introduce an optimization approach for accessing the geographic and temporal aspects of a hydrogen transport infrastructure configuration [58]. The outcomes of both studies reveal that the use of GIS is crucial when exploring the impact of the geospatial dimension of hydrogen networks and the increasing changes in energy generation mix on future energy system infrastructures and supply chains.

\section{Current Challenges in GIS-Based Planning and Modeling for Renewable Energy}

The seemingly most essential shortcoming in current energy systems research, which is mostly based on topological system models, is the lacking bridge to geospatial planning activities. In other words, energy system models are largely decoupled from the real world (in a geographical sense) as they mostly only consider topological relationships within the network, disregarding the actual topographic and geographic relationships (see Section 2). Thus, a perennial challenge is to incorporate the spatial nature of energy systems, not only considering energy-related parameters, but also geographic ones.

This requires the integration of GIS with energy system models. However, energy system researchers have acknowledged that this integration is not trivial for several reasons. First, both energy system models and geospatial analysis processes are highly complex in terms of the combination of numerous model parameters to approximate the model to the real world as best as possible without too much simplification [59].

Second, computational requirements for integrating the geospatial dimension into energy system models are enormous, due to the drastic increase of the model's complexity and the high amount of datasets necessary for fine-grained results. Geospatially and temporally fine-grained analysis results can be one of the major advancements over previous approaches that mostly either operated on a regional resolution or just examined a small area of interest.

Third, the integration of a variety of heterogeneous data structures and formats poses a major challenge in integrating energy system models and GIS [60]. This seemingly trivial engineering issue has to be tackled on a generic level to achieve a sustainable and durable solution, which is highly difficult. Subsections 4.1 and 4.2 elaborate on the substantial problems of data availability, proprietary data formats, singular data integration methods and lacking standardization in data exchange.

Fourth, a central limiting factor in using GIS-based approaches in energy infrastructure planning projects is limited data availability. In many cases, planning and optimizing energy infrastructures require a variety of data sources, including land cover, land use, building footprints, 3D building data, demographic data, like population densities, line network topologies, weather data, and others. However, these data sources are often not available or accessibility is restricted by the data providers. This limits the possibilities of the analysis methods and the accuracy of the results, as for many use cases, only a small number of data sources can be used due to high license costs. 
Fifth, an additional challenge that comes along with limited data availability is the inhomogeneity in the level of granularity with respect to both the geospatial and the attribute dimension. For instance, building-specific parameters, such as the number of floors, may be accessible in one administrative region, but not in another, whereas the number of households is not even available in one region, but accessible at the block-level in another. Thus, in order to find a common denominator in terms of a harmonized geospatial and attributive level of granularity, innovative vertical and horizontal aggregation and disaggregation mechanisms need to be developed. Further, to aim for the "highest" possible granularity within energy-relevant geo-data might not always be the "best" fit for the purpose, because of typically high license costs and privacy issues, as discussed in Subsection 4.5.

Finally, the current power market design is static and does not account for the dynamic nature of the energy market [61]. Thus, in [62], it defines five principles for qualifying the structural changes of the energy infrastructure and for mapping them into concrete policy recommendations. These principles are: (1) subsidiarity (delegation of responsibilities between network levels); (2) flexibility as an economic good (a good with spatial and temporal reference); (3) adequacy in installation and retrofitting of the energy infrastructure (regarding costs, risks, utility and limitations); (4) cost equity (equitable distribution of costs of the energy system to originators and users); and (5) incentives for innovation and investments. Even though all of these principles have an inherent geospatial reference, a GIS-supported method for new power market designs has not been defined yet.

\section{Future Research Avenues in GIS-Based Planning and Modeling for Renewable Energy}

Based on the literature review presented in Section 2, the extracted challenges described in Section 3 and practical project experiences, we extracted a number of future research avenues for integrating GIS with energy system models. These research fields, ranging from data availability and data models to 3D analysis, the integration of energy network topologies into GIS and the design of a new power market design, are described in the following subsections.

\subsection{Base Data: Geospatial Awareness, Availability, Accessibility and Openness}

Medrano et al. already stated in 2008 that, with respect to sustainable energy infrastructure planning, standardized interfaces and GIS enable interoperable data exchange among specifically designed energy models, thereby fostering GIS as being an integral component rather than a "spatially-aware add-on" [63]. Yet, one of today's essential overarching problems in using GIS in renewable energy infrastructure planning projects is the lack of relevant geodata or deficient data quality. The lack of geodata is primarily rooted in three main reasons. First, valuable datasets, such as energy and heat demands, energy production, types of home heating systems, line network structures or the energy and heat grid topologies, are mostly owned by energy providers and distribution network operators, who are often not willing to provide those data to external institutions. Second, many energy datasets, such as network topologies, have no explicit geospatial reference, as most energy system models do not take geospatial parameters into account, as shown in Subsection 2.1. Third, the inhomogeneity in the levels of detail and the non-area-wide availability of specific energy-relevant parameters are a central challenge in the context of the geospatial analysis of energy systems. For instance, the number of floors in buildings is hardly available for all buildings within a study area, although it would be 
significant for the energy demand calculation of individual buildings. This is specifically true if the study area crosses several administrative borders involving different public institutions providing the data [64]. An additional critical aspect of such fine-grained geodata analysis is privacy protection, which is discussed in Subsection 4.5.

Moreover, the concept of "open data" has recently received much attraction through its increasing importance worldwide. Open data stands for a subset of data that is freely available to everyone for use without restrictions [65]. The importance of open data is underpinned by a recent remark by the President of the World Bank, stating that "our initiatives for open information, open data, and open access to knowledge may turn out to be the most important legacy of the past five years" [66]. Although the benefits of open geodata have been proven [67-69], data providers are still reluctant to supply their data for free. This is particularly true for open government data (OGD) in that numerous open data initiatives have been launched by public bodies ([70-74]), but their effective implementation did not meet the promises made. Mostly, only coarsely-grained general data, such as digital elevation models (DEM) or small-scale administrative boundaries, are published that are oftentimes not beneficial for performing detailed and geospatially fine-grained analysis.

Although these data are valuable for analysis, such as a regional estimation of the renewable energy potential, the comparably coarsely-grained data are oftentimes not energy-specific, and their granularity is insufficient for detailed and geospatially fine-grained analysis, such as, for instance, the energy and heat demand. Instead, individual studies often have to perform their own data acquisition and mapping. Nonetheless, one step towards open energy data is the Energy Data Initiative launched by the U.S. Department of Energy as a part of the Open Government Directive [75]. The initiative aims at governmental transparency and involving the public in the transformation towards cleaner energy production. Another promising initiative, Open Energy Information (OpenEI) [76], provides a wiki-based platform for sharing energy information and data. Compared to the vast majority of other online platforms that mainly focus on single countries or regions, the OpenEI initiative is sponsored by international organizations and has contributors worldwide, which strongly increases its significance.

An additional and innovative way of energy data acquisition is to allow citizens to contribute data by means of web-based crowdsourcing and public participation platforms. Moreover, mobile technologies, such as smartphones, allow for on-site geodata acquisition, for instance, in the form of geo-referenced images in combination with a supplementary textural description. Further opportunities for making use of user-generated data are discussed in Subsection 4.3.

\subsection{Development of a Generic and Unified Data Model}

The second central research avenue, which is tightly connected with the base data issue described in the previous subsection, is the development of a generic data model that can be used for storing base data used in energy system models and other GIS-based renewable energy analysis methods and tools. Even though a number of research initiatives (EnerGEO [56], GISOPT [77], SIMMODEL [78]) have aimed to develop such a data model, no generic solution has been found in broad accordance between research institutions, public bodies and energy enterprises yet.

The unified data model needs to allow for the integration of a variety of different base data sources, including renewable energy potentials, line network topologies, meteorological data, statistical data 
(e.g., population density), building properties, 3D building models, digital surface models, energy storage facilities, power plants and energy converters and satellite imagery, amongst numerous others.

Consequently, the data model needs to be able to handle vector and raster datasets, which is still a prevailing dichotomy in the sector of geographic information (GI). Apart from this gap, the integration of vector and raster data is also a challenge from a methodological viewpoint [79], and a database viewpoint as the integration of different data types, such as geometries, XML-based formats and raster data into a single database, is highly challenging.

As an overarching, all-encompassing data model might be virtually impossible to establish for the above-mentioned reasons, it will be crucial to develop a core profile that can be extended according to the needs of a specific application. This guarantees the ability to implement the data model with reasonable effort, while still being open enough to cover a wide range of applications and energy system models. However, results from previous research projects have shown that a common agreement on a core data profile for energy-related data is hard to achieve. Thus, a bottom-up approach to the generation of a data model might be the most promising course of action, rather than a long-breathed formal top-down standardization procedure.

Another strategy to cope with the problem of the availability of highly heterogeneous datasets is to solely integrate pre-processed data into the data model rather than all the raw datasets, depending on the inputs required for a specific analysis task. For instance, if an energy system model requires building outlines to compute the passive solar energy potential of single buildings, one would not store the original LiDAR point cloud in the database, but rather store the building outlines derived from the LiDAR data. First of all, this saves memory space in the database, and second, it allows for enough flexibility in adapting the database contents to the input parameters required by the energy system model.

Concluding, it can be stated that the energy sector has not been deeply penetrated yet by geospatial data storage and modeling concepts, as opposed to numerous other application areas. Thus, future challenges will be to raise awareness for GIS-based methods and the concept of a spatial data infrastructure (SDI) for the energy sector, similarly to INSPIRE (Infrastructure for Spatial Information in Europe) [80] for environmental data exchange. As the application fields within the area of energy-related applications is extremely wide, as shown above, the preferable course of action will be to create a core profile, which is extensible according to the specific use case.

\subsection{New Data Sources: VGI and Crowdsourced Data}

Apart from dedicated and highly specialized base data, as described in Subsection 4.1, other less-official user-generated datasets are gaining importance in planning and carrying out energy infrastructure projects. Here, the concepts of volunteered geographic information (VGI) [81] and people as sensors [82] play a key role.

Both of those concepts stand for user-generated geodata that are collected in collaborative processes. This approach has three distinct advantages: First, accessibility to geospatial data is considerably increased by a new understanding of open geodata infrastructures; second, the breadth of available energy data, which has so far mostly been kept in proprietary and closed systems by energy providers and network operators, is dramatically expanded; and third, due to the increasing number of Internet users, the use of 
geodata and GIS-based tools is not only restricted any more to a small group of people with special knowledge. Together with the concept of public participation (see Subsection 4.4), which allows citizens to provide feedback with their opinions and considerations to planning processes, this can significantly lead to further democratization in planning and carrying out energy infrastructure projects.

Even though VGI is moderately used in decision-making processes in other areas ( $c p$. the fast rise of OpenStreetMap (OSM) [83,84]), the use of VGI has not been widely studied for the energy sector. Here, potentials that need to be evaluated comprise crowdsourced data, including storage facilities, private small-scale power plants, energy consumption data, measurements from private weather stations, or citizen science oriented approaches, such as the estimation of shading effects for individual buildings.

Furthermore, the use of "user-generated data" coming from smart meters that have massively entered the market needs to be investigated. These can monitor individual energy consumption in 15 min intervals or even more frequently. Smart meters offer clear benefits for electricity suppliers, who can use the real-time information on energy consumption in order to adapt their production and distribution strategies. Furthermore, electricity consumers can benefit from smart meters by monitoring their energy usage and consequently adapting their consumption towards a more efficient usage. The third EU Energy Efficiency Directive [85] defines the ambitious goal that 80 percent of European households should have smart meters installed by 2020 . This is one of the actions in order to reach the aim of a $20 \%$ reduction in energy consumption by the same year.

However, apart from the evaluation of crowdsourced data's fitness-for-use, which needs to be tackled as the case arises, a number of key questions need to be addressed. First of all, quality assurance is one of the major issues that includes research topics, such as uncertainty estimation or dynamic error detection, correction and prevention. In this research area, we are currently seeing different approaches in development, including complex event processing (CEP) for error detection, standardization efforts for representing uncertainty in geospatial data (e.g., Uncertainty Markup Language (UncertML)) [85] or proprietary profiles to define validity ranges for particular observations. Only when these questions are solved, can the reliability and completeness of VGI be ensured.

Furthermore, a central question in the context of crowdsourced data is how we can preserve people's privacy when dealing with user-generated information and partly personal data. Due to the breadth of this topic and the currently intense discussions, a separate Subsection 4.5 is dedicated to privacy-related issues.

\subsection{The Importance of GIS-Based Public Participation}

As mentioned in Section 1, the modification of the energy infrastructure necessitated by increasing renewable energy use comprises an extension of power and heat networks and the construction of additional power plants and storage facilities [2]. These massive infrastructure changes lead to rising awareness in the broader public, oftentimes raised by visual impacts caused, for instance, by wind and photovoltaic (PV) power plants or overland power lines. This also implies a transition from "energy for space" to "energy from space" [86].

This development, which also entails considerable land requirements, necessitates new regional and local negotiation processes. Governments have realized that the acceptance of energy infrastructure 
projects in the broader public is of major importance, as it strongly influences planning and investment security [87]. This is mainly due to an effect called the "NIMBY phenomenon" (not in my backyard), which has been thoroughly studied in previous scientific research [88]. This is also underpinned by Manfren et al., who state that public information and public communication will gain importance in terms of "citizen-centric" energy infrastructure planning [89].

One strategy to address the NIMBY phenomenon is offering participation possibilities for citizens in planning processes to increase transparency and to ameliorate access to information about a specific project. Here, mainly, new web-based concepts, including WebGIS, Web 2.0, Public Participation GIS (PPGIS), Government 2.0 or e-participation approaches, have been found useful. A study, which involved 377 probands [90], shows that more than $90 \%$ of the study participants in the sectors, citizens, public governments and energy industry, believe that conventional public participation methods (disclosure of project plans in the city hall, open councils, etc.) should be extended by map-based applications on the Internet, as illustrated in Figure 3.

Figure 3. Indications of whether traditional public participation methods should be extended by map-based applications on the Internet (adapted from [90]).

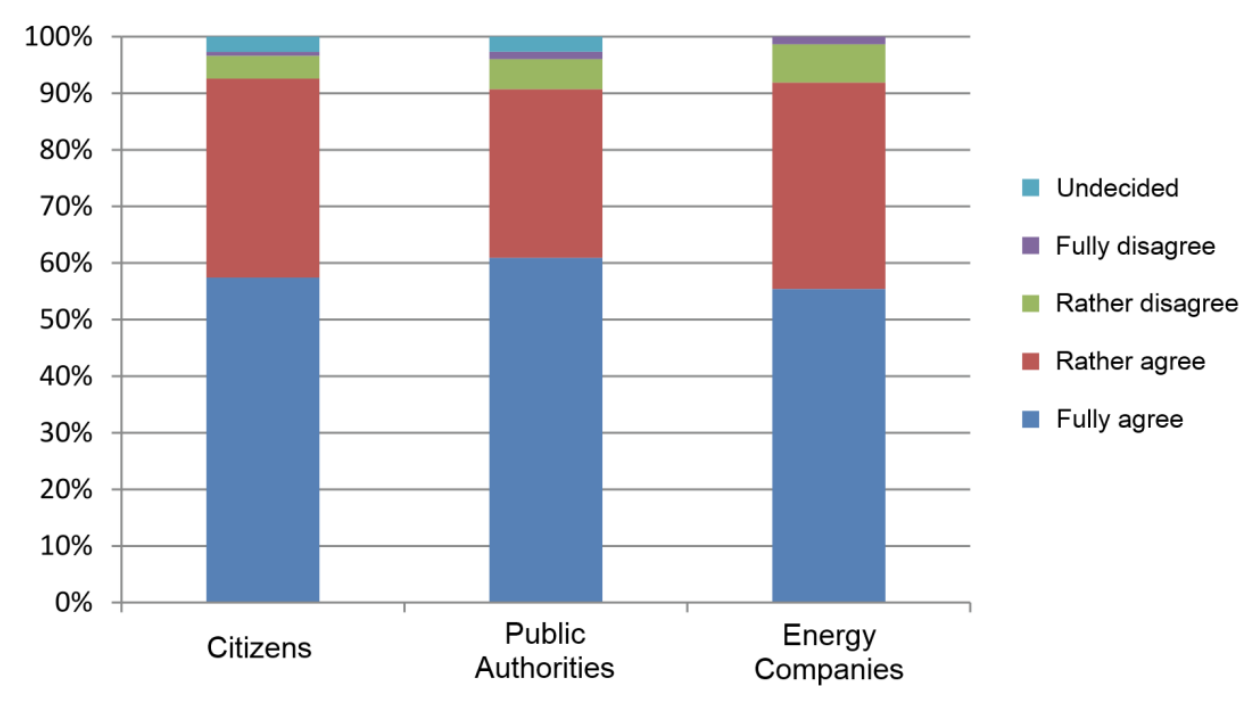

Even though numerous public participation applications have been previously developed for specific projects, nearly no research efforts exist that underpin the discussion of involving the public in decision-making in energy infrastructure projects with scientific concepts and the results of comprehensive user studies. Future research in this area includes research on the motivation for participation, the fitness of PPGIS concepts for different use cases, optimized communication between the involved parties, tailored and standardized user interface design and a set of core functional requirements.

\subsection{Privacy Concerns}

In terms of privacy, the claim might arise that we need to be aware of our personal and private data before we share them. This also raises the need to discuss the concept of I-VGI, i.e., involuntarily contributed geographic information, in contrast to VGI (cp. Subsection 4.3). For instance, collective sensing approaches exploit anonymized data from digital networks (e.g., by deducing energy demands 
from traffic traffic distribution in the cell phone network) even though people have not intended to share their data in this way.

Another central issue in using crowdsourced data is the personal impact of fine-grained analysis results, as terms like "renewable energy potential" or "energy demand" are only surrogates for a much wider influence influence on people, which raises the necessity for finding finding the right level of information provision. For instance, precise data on a household's energy consumption could be used to derive the number of people living in a household and individual patterns and habits (daily usage patterns, personal habits, etc.) [91]. Therefore, there is a need for investigating security and customer privacy related to user-generated energy data [92]. Several authors have presented ideas of how to anonymize smart meter data between the customer and third parties [93,94], but those are just singular technical approaches.

Consequently, more accurate, finerfiner-grained or more complete information might in many cases not necessarily be worthwhile having, as this could allow for drawing conclusions on a very small scale, in extreme cases, even on the individual. This again could entail a dramatic impact in a very wide range of areas, like housing markets, subsidization conditions, the insurance sector or urban planning and management.

The issue of data privacy also applies to other energy-related data. These include more detailed information regarding building heat demand and the energy production from privately owned photovoltaic power plants. Even if the energy consumption and heat demand would be available on a building level, privacy issues would restrain the use of the data for third parties. New approaches to privacy protection are therefore necessary. Krüger and Kolbe model the city-wide energy demand of Berlin based on the characteristics of single buildings [95]. Yet, the authors state that real values cannot be computed due to privacy issues.

Thus, as energy infrastructure planning processes oftentimes deal with personal or individually significant data, legal frameworks have to be developed on national, trans-national and global levels to protect those data. The largest limiting factor in this regard is the varying interpretation of "privacy" in different parts of the world. For instance, privacy can be traded like an economic good by its owner in the USA, whereas it is protected by law in the European Union. This means that supra-national legislation bodies and initiatives are called upon to set up appropriate world-wide regulations, even though legislation and governments play a highly different role in these two settings.

This also includes the critical question of data ownership; who owns the data: the data producers (i.e., the citizens or an energy provider), the institutions that host a system to collect data or the data providers? Furthermore, if sensitive data is analyzed to produce planning-relevant information layers, who is responsible if decisions that are based on this information are wrong due to the lack of quality of the base data? In conclusion, the issues of privacy, data ownership, accessibility, integrity and liability have to be tackled thoroughly all at once and not separately from each other.

\subsection{D Building Models and 3D Data Analysis}

Recently, energy models, which operate at different scales (regional, urban, local, building), are being harmonized. This means that GIS-based approaches are combined with building information modeling (BIM) based methods in energy system modeling and analysis [96]. Currently, we are 
witnessing the fast rise of the usage of 3D building models for the calculation of solar potential using façade visibility. There are a number of GIS and BIM-based methods for single buildings or larger areas on various scales [97-99].

Furthermore, 3D building and air transport models are used to calculate the energy demand of buildings [100,101]. The fields of application are the design of innovative remediation concepts of urban areas and the development of heat and energy network expansion strategies. In these fields, an overview of the current heat demand, as well as an efficient way to calculate and visualize remediation scenarios is urgently needed.

Apart from 3D building models, 3D analysis algorithms will play a key role in future energy system modeling. Jochem et al. present a first approach in this direction [102], but there is a growing need for more holistic and fine-grained analysis methods. Future research challenges include the integration of ray tracing algorithms [103], the analysis of high-resolution building data [104], the integration of building part parameters, like walls, windows, line networks, etc. [105], the seamless cross-integration of BIM and GIS [106] and the consideration of the three-dimensional characteristics of power generation of renewable energy sources [107]. Most of these challenges have been tackled earlier in singular approaches, but no integrative method has been found so far.

\subsection{Integration of Network Topologies into GIS}

The distributed generation (DG) of energy, specifically in the form of electricity and heat, typically requires grid-connected technologies, i.e., pipelines, cables, and appropriate storage technologies in order to transport electrical or heat energy from where it is generated to where it is needed. As stated in [108], "the use of GIS, together with models that describe the resources' availability and complementary economic and environmental models, can be used to identify the regional areas where DG production becomes attractive (and is therefore likely to be realized), requiring connections to the grids".

Topological properties, such as connectivity, proximity and adjacency, play a central role in the optimization of grid-connected energy networks [109]. Finding the optimal location, size and technology of energy storages within such a connected network is crucial in balancing spatial, temporal and spatio-temporal load shifts, in particular when decentralized energy sources are involved. For instance, the connectivity among segments of the distance heat network must be given in order to accurately calculate and consequently compensate for temperature losses. The proximity of potential renewable energy sites or potential expansion areas to existing energy infrastructure is important to correctly assess costs, such as installation and maintenance costs, and to avoid any disturbance with other nearby areas, e.g., specific animal habitats. Adjacency can be used to evaluate whether, for instance, neighboring parcels or areas share a common border with the potential energy production site, as this might be critical to legal means.

Geodata of energy networks are typically represented as lines or polylines (a line with several vertices between the starting point and the endpoint of the line). Although almost all such network data are managed with some kind of digital system, they are typically not "clean" in terms of topological properties, e.g., due to non-accurate manual or automated digitization processes. For instance, two lines (or line segments) are not topologically connected to each other, because they do not share the 
exact same point, even though it may visually seem correct. However, GIS and geospatial database management systems provide tools to correct such errors with user-defined parameters, e.g., two points that lie within a certain distance will be merged into a single point or two almost identical line segments of two adjacent areas are merged into one single line, segment since that segment represents a common border. In this way, the reconstruction of a topologically correct and "clean" energy network graph, which consists of nodes and edges, is also the basis for GIS-based energy system analysis, such as shortest path analysis and more complex computations regarding network performance and network reliability, particularly with respect to the spatio-temporal fluctuation of network load.

From a more detailed energy system point of view, topological properties should also be considered, in principle, within small and local energy network components, such as pipes from, for instance, the solar-thermal plant on the rooftop to the hot water tank. The actual metric distance between the energy components involved is not critical in terms of energy losses. However, whether or not a specific component is part of the network might be crucial. With respect to a multi-step network analysis, a binary answer to a question like "which houses are connected to that part of the energy network" can then be used for further, more detailed, investigation.

With respect to monitoring an operational energy network's performance and fluctuation, the real-time coupling of energy systems and GIS in necessary in order to effectively and efficiently resolve both unexpected and expected challenges in energy supply; for instance, interrupted power lines or the damage of essential energy hubs, due to thunderstorms or landslides. A forecasted cold front can be analyzed and visualized using real-time GIS [110,111]. On a technical level, such a real-time coupling of diverse systems requires interoperable data and information exchange based on standardized interfaces and services. In turn, this also necessitates the coupling of GIS with supervisory control and data acquisition (SCADA) systems, as SCADA systems' primary purpose is to monitor a building's state, including the surveillance of the energy infrastructure. This issue is tightly coupled with the transition from structural planning to operational control in energy systems, as described in Subsection 4.11.

\subsection{Aggregation: Combining the Energy and GIS Views}

Modeling an energy system requires a high variety of different base data. For many regions, datasets, like energy production, installed PV power plants or population densities, are available on a community level. Depending on the data provider and the original usage and purpose of the data, a broad variety in the scale can be expected. For instance, data at the level of individual buildings have a high accuracy. A disadvantage at this scale, however, is that the data tend to be commercial and costly. Furthermore, some of the desired attributes might only be partly available. At this level, also, privacy issues are of concern. When moving towards the block and postal code level, a loss in geospatial accuracy is expected. Depending on the purpose of the study (e.g., a general estimation of the heat demand for a possible expansion of the district heating grid), this level may still be appropriate. For other purposes (e.g., a more exact positioning of decentralized energy storage facilities), this scale may be too coarse. As an example, Figure 4 shows different scales and relevant data for the estimation of the building heat demand. 
Figure 4. An example of different scales and relevant data when modeling an energy system. The example shows relevant data when simulating the building heat demand at different scales and geospatial accuracies.

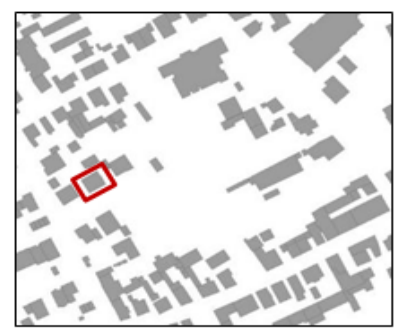

Building, attributes: geometry, year of construction, building type, ground area, height, nr. of floors, direction etc.

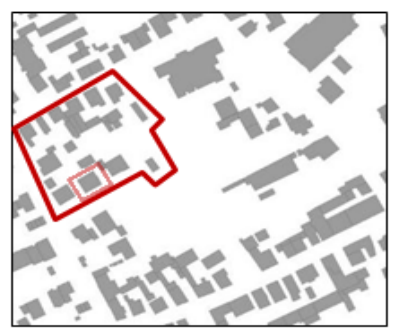

City block, attributes: population density, block type etc.

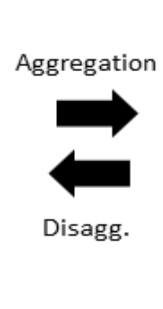

Disagg.

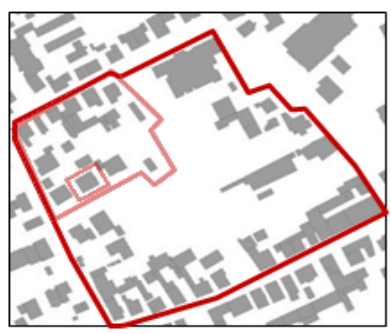

Postal code, attributes: population density, generalised building type, energy consumption etc.

As a consequence, when coupling energy planning and GIS, there are at least three reasons why one would have to work on different spatial scales and to aggregate or disaggregate the data: (1) a common scale (e.g., building level or district level) for all the data is required for the analysis or validation of the results [112-114]; (2) a faster computing time is desired [115]; (3) consideration of data privacy aspects are required $[93,94]$.

Hence, it is essential to apply methods that can store and process data at different scales. One option is to apply a geospatial database having a hierarchical structure in which the smaller units all are part of larger units [114]. The data of the smaller units (e.g., districts) could then be aggregated to larger units (e.g., states) based on SQL queries. The same principle could also be applied to scales of finer resolution, including city district, housing block, street sections and individual buildings, among others. Another option for aggregation is to apply a regular grid on a lower resolution than the original data, e.g., $100 \mathrm{~m}$ by $100 \mathrm{~m}$ for the modeling and visualizing of heat and energy demand [116].

Instead, disaggregation has to be conducted based on an explanatory variable. With regards to energy demand, this could be population distribution, building density or household members and building types [117]. Hence, by assuming a relationship between population density and energy demand, the energy data could be disaggregated to a finer resolution. Another example would be to disaggregate time series of total regional photovoltaic energy production (as often available from network operators) to single photovoltaic panels with known effects. The later data are available from several, often region-specific, online services, including the San Francisco Energy Map [118] and the Solar Essence [119] in the U.K. This approach would result in a disaggregated geospatial data set representing the decentralized energy production. At the same time, it would retain privacy, since the energy production of each single photovoltaic panel is an approximation based on the assumption that it is linearly related to the total production of the surroundings. Nonetheless, such a fine-scaled geospatial data set could be a valuable input parameter to a wide range of energy models. One challenge, however, is to create a complete database that includes the data from several photovoltaics installers. One approach could be to include crowdsourced information, like the Open PV Project [120] and the KliBA (Klimaschutz- und Energie- Beratungsagentur Heidelberg- Rhein- Neckar- Kreis $\mathrm{gGmbH})$ initiative [121]. 


\subsection{Fine-Grained Energy Demand Estimation from Freely-Available Data Sources}

Energy demand and potential analysis is an established planning tool at local and regional levels [27]. This analysis forms an important basis for the derivation of supply concepts and mitigation measures. Therefore, the bandwidth of the methods and approaches used for energy and heat demand assessment is large, and a comparison of the results is oftentimes not possible. One of the reasons of this shortcoming is the fact that planning objectives are mostly defined by the required base data and the methodological approaches used, which limits the scope and the prospects of the analysis process.

While at a regional scale, mainly statistical data in connection with simple cartographic visualization are used, GIS-based approaches dominate applications only at a local scale [122]. So far, these GIS-based studies are mainly confined to the estimation of the heat demand of residential buildings. Typical studies aim to improve the statements of the heat demand of individual buildings in very small areas. Here, a new and innovative approach would be using a combined top-down and bottom-up process to link cadastral data at the building level with macro-scale statistical data and present the results as a high-resolution heat atlas. Surprisingly, despite significant deviations of the heat demand for individual buildings, the statistical variations in aggregated geospatial units can be expected to be low. The advantage of this approach lies in the homogeneity of the base data and the comparability of the results beyond the local scale.

Yet, the possibilities of the use of geospatial data and geographic information systems are still far from exhausted. Many applications are limited by the lack of accessibility of necessary base data (energy systems data and geodata). As a consequence, energy demand studies at the local level can only be incomplete or conducted with considerable expense for additional data sources, such as residential buildings, the energy demand of transport, industry, services or trade. Thus, the accessibility of base data on energy consumption needs to be further improved in order to ensure the planning decentralized energy systems with a high share of renewable energy sources.

\subsection{Planning of Decentralized Storage Facilities}

Planning decentralized storage facilities greatly depends on structural, technological and economic issues. The planning process begins with the estimation of energy demands of the buildings in urban regions. Due to data privacy laws, the measured data of energy consumption can rarely be used for the calculations (Section 4.5). Therefore, yearly heat energy loads are estimated with the suggestions in [123]. The loads vary broadly with building standards and the year of construction.

Beside the spatial distribution of buildings with certain standards and its heat energy loads, the time-dependent heat loads are important for the integration of thermal heat storages in urban regions. Thermal storages can cover heat loads in times with high heat energy consumption and charged in periods with a low consumption. The operation of heat energy storages within an energy system is a time-dependent matter. Therefore, heat energy loads and domestic hot water profiles in an hourly resolution need to be generated based on mathematical models [124-127].

Once the heat load profiles are generated, the whole energy system has to be defined under consideration of spatial and operational aspects with an iterative multi-criteria-optimization [128]. 
Thereby, the concept of distributed thermal energy storages is an important part of the optimal storage facility planning.

The optimization model shows the optimal storage capacities in the urban region. The volumetric capacity identifies whether the calculated storage capacity fits in the calculated site or not. Moreover, the flow temperatures within a district heating network or a building identify the optimal storage technology. Moreover, the power rate, the efficiency, the time period of energy storage and the costs determine the right storage capacity (Table 1). Further, the land use of the area of future thermal energy storages has to be anchored in building permissions and public participation (see Section 4.4).

Thermal energy storages and their distribution within an energy system represent one possibility to improve the overall energy efficiency within a local energy system. When thermal storages are discharged in peak load times, oil-driven boilers can be replaced. The base load for heat is covered with combined heat and power plants (CHP), whereby the simultaneously produced electricity is supplied to the electricity network [129]. Due to the rising share of the fluctuating energy resources, the combination of CHP and well-planned thermal energy storage facilities ensure grid stability. Operating CHPs in high price periods within a day ahead market is an opportunity to grant energy supply to the electricity grid [130,131].

Furthermore, electrical storage is an important element for supplying balanced and control energy in a future European energy supply scheme [132,133]. In small-scale urban regions, especially capacitive reactive power is reduced with electrical storages placed at consumer sites, and the time-variant load situation has to be evaluated with mathematical network models considering electricity supply and demands [134].

Table 1. Storage technologies with technical and economic characteristics for both thermal and electrical storages [135].

\begin{tabular}{lccccc}
\hline Technology & $\begin{array}{c}\text { Capacity } \\
(\mathbf{k W h} / \mathbf{t})\end{array}$ & $\begin{array}{c}\text { Power-Rate } \\
(\mathbf{M W})\end{array}$ & Efficiency $(\%)$ & $\begin{array}{c}\text { Storage } \\
\text { Duration }\end{array}$ & $\begin{array}{c}\text { Costs } \\
(\boldsymbol{\epsilon} / \mathbf{k W h})\end{array}$ \\
\hline Thermal: & & & & & \\
\hline Sensible & $10-50$ & $0.001-10$ & $50-90$ & day-month & 0.1 \\
Latent & $50-150$ & $0.001-1$ & $75-90$ & hour-week & $10-50$ \\
Thermochemical & $120-250$ & $0.01-1$ & 100 & hour-day & $8-40$ \\
Electrical: & & & & & \\
Lithium ion & 130 & $0.02-? ?$ & 90 & day-month & 1000 \\
Lead acid & 40 & - & 85 & day-month & 200 \\
NaS & 110 & $0.05-? ?$ & 85 & day & 300 \\
Redox flow & 25 & $0.01-10$ & 75 & day-month & 500 \\
\hline
\end{tabular}

Table 1 lists the most promising technologies of electrical storage that may be used in the future research efforts. Compared to the costs of thermal energy storage and the current gas prices, electrical storage represents only a long-term option for balancing loads within the electrical grid [133]. This matter is also discussed in Subsection 4.12. 


\subsection{From Purely Structural Planning towards Operational Planning}

So far, most optimization methods for energy systems focused on structural network and facility planning. Recently, operational planning is gaining importance, as this new paradigm ensures a reliable and cost-effective operation of energy supply systems. Yet, the operational optimization of entire energy systems can only be realized with complex various energy-economic models [27,136,137]. The efforts in optimization range from the operational planning of distributed energy systems (DES) under the consideration of costs for fuels, maintenance and the investment [129] for integrating high price scenarios in which CHP units produce electricity related to the market situation in a deregulated electricity market $[130,131,138]$.

A rising research area, called "short time periods" of operational planning refers to the method of "model predictive control" (MPC). It is mainly based on real-time data and shows the actual state of an energy system [139]. With predictions on a minute and hourly basis, MPC defined control strategies for the near future on the fly. When operational planning involves long time periods and issues for investment, it can be treated as a deterministic approach, whereby all parameters and time-dependent data are fixed [140]. Deterministic approaches also enable case studies and sensitivity analysis in urban energy systems for the future development of the fluctuating electricity supply and refurbishment measurements in the existing building stock [141].

According to $[142,143]$, structural planning can only be performed effectively when combined with operational optimizations. Sets of various spatial distributions of heat pumps and combined heat and power plants are integrated in operational optimizations. The results allow decisions between the various spatial planning strategies, e.g., about the installation of centralized or decentralized energy sources [144]. The work in [145] lines up a decomposition method, including spatial, as well as operational optimization of energy systems. A more sophisticated approach in structural planning with a broad variance for the distribution of district heating networks and thermal energy storages is presented in [146,147].

Möller claims that "heat atlases finally must provide a better basis for making energy systems analysis with computer models" and the needs for GIS-based planning tools dealing with operational and structural planning algorithms in energy systems are underwritten [148]. The work of [149] presents a geographical information based system, which evaluates the efficiency of the spatial distribution of heat pumps in urban regions. All of these new approaches open up new research avenues for GIS-based approaches as real-time information is meanwhile a vital part of many GIScience research projects from which the energy domain can benefit.

\subsection{Towards a New, Dynamic Power Market Design}

According to [62,150] and [151], the structural change that is being induced by the political commitment to the energy turnaround ( $c p$. Section 1) has drastic impacts in three distinct areas: (1) energy supply security (stable energy supply is a basic requirement for economic and private life); (2) profitability (international compatibility can be guaranteed only by socially acceptable energy prices); and (3) environmental sustainability (environmental protection is indispensable for sustainable energy supply in consideration of energy efficiency, emission reduction and economic use of resources). 
Thus, a major future research avenue is the establishment of a new power market design and an investigation of its implications for innovative business models, particularly considering the geospatial view rather than exclusively an energy systems view. Here, key aspects include capacity planning (GIS-based economic optimization of production and storage capacities, as well as transport and distribution networks), division of responsibilities (due to the increasing volatility of the power market induced through renewable energy sources, responsibilities need to be divided between the market and legislation) and new market designs and business models (exploitation of new typologies, including aggregators, virtual power plants, swarm storage facilities).

In these open questions, GIS can potentially play a vital role through the integration of geo-social networks (Internet-based communication across system borders as a new means of handling transactions), integration of "digital citizens" (citizens proactively contributing to public participation processes through web-based and mobile technologies; $c p$. Subsection 4.4), customization and simplification (personalized services) and the integration of the Internet of Things (using sensors and actuators for operational planning and dynamic energy pricing).

\section{Conclusions}

In the face of the broad political call for an "energy turnaround", we are currently witnessing three essential trends with regard to energy infrastructure planning, renewable energy generation and storage: from planned production towards fluctuating production caused by renewable energy sources, from centralized generation towards decentralized generation and from expensive energy carriers towards cost-free renewable energy carriers. These changes necessitate considerable modifications of the energy infrastructure.

Even though most of these modifications are inherently motivated by geospatial questions and challenges, the integration of energy system models and GIS is still in its infancy. From a more general point of view, integrating GIS with energy system modeling enables the generation of a more complete picture of the overall energy system and future "energy landscapes" [26]. We claim that it is not enough to consider space and time as additional parameters, but in fact, space and time need to be fully integrated into energy system modeling processes in order to better understand the spatio-temporal dynamics of, for instance, energy demand, availability and the effectiveness of conventional and renewable resources, capacity and load-patterns of energy infrastructures, including decentralized energy storages and, finally, the return of investments and economic profitability.

This paper analyzed the shortcomings of previous approaches in using GIS in renewable energy modeling and planning efforts, extracted distinct challenges from these previous approaches and, finally, defined a set of core future research avenues for GIS-based energy infrastructure planning with a focus on the use of renewable energy. These future research avenues comprise the availability base data and their "spatial awareness", the development of generic and unified data model, the usage of VGI and crowdsourced data into analysis processes, the integration of 3D building models and 3D data analysis, the incorporation of network topologies into GIS, the harmonization of the energy and GIS views on aggregation issues, fine-grained energy demand estimation from freely-available data sources, decentralized storage facility planning, the investigation of GIS-based public participation 
mechanisms, the transition from purely structural to operational planning, privacy aspects and, finally, the development of a new dynamic power market design.

\section{Acknowledgements}

The authors would like to thank all involved research groups at Harvard University's Center for Geographical Analysis and at Heidelberg University for offering their valuable thoughts. Furthermore, a special "thank you" goes to Bernhard Höfle, who offered us valuable feedback throughout the revision process. This research has been supported by the Klaus Tschira Stiftung gGmbH and by the Baden-Württemberg Programme "Lebensgrundlage Umwelt und ihre Sicherung (BWPLUS)".

\section{Author Contributions}

Bernd Resch initiated the idea and the concept of the paper, was responsible for writing the major part of the paper (Sections 1, 3 and 5, Subsections 4.1-4.5, parts of Subsection 4.6, 4.12), supported the writing of all other sections, and took care of editorial and proof-reading issues. Günther Sagl is the main author of Section 2 and Subsection 4.7, and contributed to Sections 1 and 3, and to Subsection 4.12. Tobias Törnros authored Subsection 4.8 and contributed major parts to Section 2 and Subsection 4.5. The Fraunhofer Insitute for Solar Energy Systems (ISE) contributed mainly in the field of the operational planning of decentralized storages. Andreas Bachmaier did the research, structuring and writing of the contents, Jan-Bleicke Eggers and Sattaya Narmsara gave the inputs for energy system modeling and GIS-based developments. A critical revision was done by Sebastian Herkel. Hartmut Gündra contributed to Subsections 4.6 and 4.9.

\section{Conflicts of Interest}

The authors declare no conflict of interest.

\section{References and Notes}

1. Appelrath, H.-J., Kagermann, H., Mayer, C., Eds.; Future Energy Grid-Migration to the Internet of Energy; Acatech: Munich, Germany, 2012.

2. Sachverständigen Rat für Umweltfragen (SRU). Wege zur 100\% Erneuerbaren Stromversorgung; Erich Schmidt Verlag: Berlin, Germany, 2011.

3. Mirhosseini, M.; Sharifi, F.; Sedaghat, A. Assessing the wind energy potential locations in province of Semnan in Iran. Renew. Sustain. Energy Rev. 2011, 15, 449-459.

4. Schardinger, I.; Botzenhart, F.; Biberacher, M.; Hamacher, T.; Blaschke, T. Integrating spatial models into regional energy system optimisation: Focusing on biomass. Int. J. Energy Sector Manag. 2012, 6, 5-32.

5. Mondal, M.A.H.; Denich, M. Assessment of renewable energy resources potential for electricity generation in Bangladesh. Renew. Sustain. Energy Rev. 2010, 14, 2401-2413.

6. Grassi, S.; Chokani, N.; Abhari, R. Large scale technical and economic assessment of wind energy potential with a GIS tool: Case study Iowa. Energy Policy 2012, 45, 58-73. 
7. Grassi, S.; Junghans, S.; Raubal, M. Estimating Mean Annual Energy Production of Clustered Wind Turbines with GIS. In Proceedings of the 2013 International Conference on Applied Energy, Pretoria, South Africa, 1-4 July 2013.

8. Chen, Y.; Li, X.; Zheng, Y.; Guan, Y.; Liu, X. Estimating the relationship between urban forms and energy consumption: A case study in the Pearl River Delta, 2005-2008. Landsc. Urban Plan. 2011, 102, 33-42.

9. Parshall, L.; Gurney, K.; Hammer, S.A.; Mendoza, D.; Zhou, Y.; Geethakumar, S. Modeling energy consumption and $\mathrm{CO}_{2}$ emissions at the urban scale: Methodological challenges and insights from the United States. Energy Policy 2010, 38, 4765-4782.

10. Blesl, M.; Kempe, S.; Huther, H. Capture of spatial high-resolution building heating energy demand. Euroheat Power 2010, 39, 28-33.

11. Van Hoesen, J.; Letendre, S. Evaluating potential renewable energy resources in Poultney, Vermont: A GIS-based approach to supporting rural community energy planning. Renew. Energy 2010, 35, 2114-2122.

12. Schoof, M.; Resch, B.; Ludwig, D. A GIS-based concept for solar energetic examination of new building projects. gis.SCIENCE 2013, 3, 97-103.

13. Sliz-Szkliniarz, B.; Vogt, J. GIS-based approach for the evaluation of wind energy potential: A case study for the Kujawsko-Pomorskie Voivodeship. Renew. Sustain. Energy Rev. 2011, 15, 1696-1707.

14. Howard, B.; Parshall, L.; Thompson, J.; Hammer, S.; Dickinson, J.; Modi, V. Spatial distribution of urban building energy consumption by end use. Energy Build. 2012, 45, 141-151.

15. Fabbri, K.; Zuppiroli, M.; Ambrogio, K. Heritage buildings and energy performance: Mapping with GIS tools. Energy Build. 2012, 48, 137-145.

16. Kolter, J.; Ferreira, J. A Large-Scale Study on Predicting and Contextualizing Building Energy Usage. In Proceedings of the Twenty-Fifth AAAI Conference on Artificial Intelligence, San Francisco, CA, USA, 7-11 August 2011.

17. Van Haaren, R.; Fthenakis, V. GIS-based wind farm site selection using spatial multi-criteria snalysis (SMCA): Evaluating the case for New York State. Renew. Sustain. Energy Rev. 2011, 15, 3332-3340.

18. Stoms, D.M.; Dashiell, S.L.; Davis, F.W. Siting solar energy development to minimize biological impacts. Renew. Energy 2013, 57, 289-298.

19. Höhn, J.; Lehtonen, E.; Rasi, S.; Rintala, J. A geographical information system (GIS) based methodology for determination of potential biomasses and sites for biogas plants in Southern Finland. Appl. Energy 2014, 113, 1-10.

20. Carneiro, C.; Morello, E.; Ratti, C.; Golay, F. Solar Radiation over the Urban Texture: LIDAR Data and Image Processing Techniques for Environmental Analysis at City Scale. In 3D Geo-Information Sciences; Lee, J., Zlatanova, S., Eds.; Springer: Berlin-Heidelberg, Germany, 2009; pp. 319-340.

21. Molina-Ruiz, J.; Martínez-Sánchez, M.J.; Pérez-Sirvent, C.; Tudela-Serrano, M.L.; García Lorenzo, M.L. Developing and applying a GIS-assisted approach to evaluate visual impact in wind farms. Renew. Energy 2011, 36, 1125-1132. 
22. Rodrigues, M.; Montañés, C.; Fueyo, N. A Method for the assessment of the visual impact caused by the large-scale deployment of renewable-energy facilities. Environ. Impact Assess. Rev. 2010, 30, 240-246.

23. Grassi, S.; Friedli, R.; Grangier, M.; Raubal, M. Institute of Geography-GIScience, Heidelberg University, Heidelberg, Germany. Unpublished work, 2014.

24. Hammons, T.J. Integrating renewable energy sources into European grids. Int. J. Electr. Power Energy Syst. 2008, 30, 462-475.

25. Føyn, T.; Karlsson, K.; Balyk, O.; Grohnheit, P.E. A global renewable energy system: A modelling exercise in ETSAP/TIAM. Appl. Energy 2011, 88, 526-534.

26. Blaschke, T.; Biberacher, M.; Gadocha, S.; Schardinger, I. "Energy landscapes": Meeting energy demands and human aspirations. Biomass Bioenergy 2013, 55, 3-16.

27. Connolly, D.; Lund, H.; Mathiesen, B.V.; Leahy, M. A review of computer tools for analysing the integration of renewable energy into various energy systems. Appl. Energy 2010, 87, 1059-1082.

28. Biegler, L.T.; Grossmann, I.E. Retrospective on optimization. Comput. Chem. Eng. 2004, 28, 1169-1192.

29. Gnüchtel, S. Vorlesung, Methoden der Optimierung von Energiesystemen. Insitut für Energietechnik, TU Dresden. Available online: http://tu-dresden.de (accessed on 12 February 2014).

30. Zhou, Z.; Liu, P.; Li, Z.; Ni, W. An engineering approach to the optimal design of distributed energy systems in China. Appl. Therm. Eng. 2013, 53, 387-396.

31. Caldera, M.; Corgnati, S.P.; Filippi, M. Energy demand for space heating through a statistical approach: Application to residential buildings. Energy Build. 2008, 40, 1972-1983.

32. Robinson, D.; Campbell, N.; Gaiser, W.; Kabel, K.; Lemouel, A.; Morel, N.; Page, J.; Stankovic, S.; Stone, A. SUNtool-A new modelling paradigm for simulating and optimising urban sustainability. Solar Energy 2007, 81, 1198-1211.

33. Robinson, D.; Haldi, F.; Kämpf, J.; Leroux, P.; Perez, D.; Rasheed, A.; Wilke, U. CitySim: Comprehensive Micro-Simulation of Resource Flows for Sustainable Urban Planning. In Proceedings of the 11th International IBPSA Conference, Building Simulation, Glasgow, Scotland, 27-30 July 2009; pp. 1083-1090.

34. Wille-Haussmann, B.; Erge, T.; Wittwer, C. Decentralised optimisation of cogeneration in virtual power plants. Sol. Energy 2010, 84, 604-611.

35. Baños, R.; Manzano-Agugliaro, F.; Montoya, F.G.; Gil, C.; Alcayde, A.; Gómez, J. Optimization methods applied to renewable and sustainable energy: A review. Renew. Sustain. Energy Rev. 2011, 15, 1753-1766.

36. Garcia, H.E.; Mohanty, A.; Lin, W.-C.; Cherry, R.S. Dynamic analysis of hybrid Energy systems under flexible operation and variable renewable generation-Part I: Dynamic performance analysis. Energy 2013, 52, 1-16.

37. Garcia, H.E.; Mohanty, A.; Lin, W.-C.; Cherry, R.S. Dynamic analysis of hybrid energy systems under flexible operation and variable renewable generation-Part II: Dynamic cost analysis. Energy 2013, 52, 17-26.

38. Henning, H.M.; Palzer, A. A Comprehensive model for the German electricity and heat sector in a future energy system with a dominant contribution from renewable energy technologies_-Part I: methodology. Renew. Sustain. Energy Rev. 2014, 30, 1003-1018. 
39. Blarke, M.B.; Lund, H. The effectiveness of storage and relocation options in renewable energy systems. Renew. Energy 2008, 33, 1499-1507.

40. Rodríguez-Hidalgo, M.C.; Rodríguez-Aumente, P.A.; Lecuona, A.; Legrand, M.; Ventas, R. Domestic hot water consumption vs. solar thermal energy storage: The optimum size of the storage tank. Appl. Energy 2012, 97, 897-906.

41. Viral, R.; Khatod, D.K. Optimal planning of distributed generation systems in distribution system: A review. Renew. Sustain. Energy Rev. 2012, 16, 5146-5165.

42. Alarcon-Rodriguez, A.; Ault, G.; Galloway, S. Multi-objective planning of distributed energy resources: A review of the state-of-the-art. Renew. Sustain. Energy Rev. 2010, 14, 1353-1366.

43. Chesi, A.; Ferrara, G.; Ferrari, L.; Magnani, S.; Tarani, F. Influence of the heat storage size on the plant performance in a smart user case study. Appl. Energy 2013, 112, 1454-1465.

44. Aydin, N.Y.; Kentel, E.; Sebnem Duzgun, H. GIS-based site selection methodology for hybrid renewable energy systems: A case study from Western Turkey. Energy Convers. Manag. 2013, 70, 90-106.

45. Janke, J.R. Multicriteria GIS modeling of wind and solar farms in Colorado. Renew. Energy 2010, 35, 2228-2234.

46. Connolly, D.; MacLaughlin, S.; Leahy, M. Development of a computer program to locate potential sites for pumped hydroelectric energy storage. Energy 2010, 35, 375-381.

47. Ramachandra, T.V.; Shruthi, B.V. Spatial mapping of renewable energy potential. Renew. Sustain. Energy Rev. 2007, 11, 1460-1480.

48. Zambelli, P.; Lora, C.; Spinelli, R.; Tattoni, C.; Vitti, A.; Zatelli, P.; Ciolli, M. A GIS decision support system for regional forest management to assess biomass availability for renewable energy production. Environ. Model. Softw. 2012, 38, 203-213.

49. Kaundinya, D.P.; Balachandra, P.; Ravindranath, N.H.; Ashok, V. A GIS (geographical information system)-based spatial data mining approach for optimal location and capacity planning of distributed biomass power generation facilities: A case study of Tumkur District, India. Energy 2013, 52, 77-88.

50. Zhang, F.; Johnson, D.M.; Sutherland, J.W. A GIS-based method for identifying the optimal location for a facility to convert forest biomass to biofuel. Biomass Bioenergy 2011, 35, 3951-3961.

51. Sultana, A.; Kumar, A. Optimal siting and size of bioenergy facilities using geographic information system. Appl. Energy 2012, 94, 192-201.

52. Kucuksari, S.; Khaleghi, A.M.; Hamidi, M.; Zhang, Y.; Szidarovszky, F.; Bayraksan, G.; Son, Y.-J. An integrated GIS, optimization and simulation framework for optimal PV size and location in campus area environments. Appl. Energy 2014, 113, 1601-1613.

53. Nielsen, S.; Möller, B. GIS based analysis of future district heating potential in Denmark. Energy 2013, 57, 458-468.

54. Biberacher, M.; Hausl, S. Räumliche Aspekte in der Regionalen Energiesystemoptimierung. In Angewandte Geoinformatik AGIT 2012; Strobl, J., Blaschke, T., Griesebner, G., Eds.; Wichmann Verlag: Berlin, Germany, 2012; pp. 290-304. 
55. Omitaomu, O.A.; Blevins, B.R.; Jochem, W.C.; Mays, G.T.; Belles, R.; Hadley, S.W.; Harrison, T.J.; Bhaduri, B.L.; Neish, B.S.; Rose, A.N. Adapting a GIS-based multicriteria decision analysis approach for evaluating new power generating sites. Appl. Energy 2012, 96, 292-301.

56. EnerGEO Consortium. The EnerGEO FP7 Project. Available online: http://www.energeo-project.eu (accessed on 30 October 2013).

57. Strachan, N.; Baltaozkan, N.; Joffe, D.; McGeevor, K.; Hughes, N. Soft-linking energy systems and GIS models to investigate spatial hydrogen infrastructure development in a low-carbon UK energy system. Int. J. Hydrog. Energy 2009, 34, 642-657.

58. Ball, M.; Wietschel, M.; Rentz, O. Integration of a hydrogen economy into the German energy system: An optimising modelling approach. Int. J. Hydrog. Energy 2007, 32, 1355-1368.

59. Oldewurtel, F.; Parisio, A.; Jones, C.N.; Gyalistras, D.; Gwerder, M.; Stauch, V.; Lehmann, B.; Morari, M. Use of model predictive control and weather forecasts for energy efficient building climate control. Energy Build. 2012, 45, 15-27.

60. Cuca, B.; Sesana, M.M.; Iannaccone, G.; Oreni, D.; Caccavelli, D. Integration of the Multi-Scale Heterogeneous Data for the Deployment of the Concept of Energy Efficiency in Buildings within an SDI Framework. In Computational Science and Its Applications-ICCSA 2013; Murgante, B., Misra, S., Carlini, M., Torre, C., Nguyen, H.-Q., Taniar, D., Apduhan, B.O., Gervasi, O., Eds.; Springer: Berlin, Germany, 2013; pp. 358-374.

61. Ventosa, M.; Baillo, A.; Ramos, A.; Rivier, M. Electricity market modeling trends. Energy Policy 2005, 33, 897-913.

62. BDI Arbeitskreis Internet der Energie. Impulse für eine Smarte ENERGIEWENDE: Handlungsempfehlungen für ein IKT-gestütztes Stromnetz der Zukunft. Available online: http://www.bdi-ide.de/beiträge/bdi-ide-publikationen (accessed on 31 October 2013).

63. Medrano, M.; Brouwer, J.; Carreras-Sospedra, M.; Rodriguez, M.A.; Dabdub, D.; Samuelsen, G.S. A Methodology for developing distributed generation scenarios in urban areas using geographical information systems. Int. J. Energy Technol. Policy 2008, 6, 413-434.

64. Mittlboeck, M.; Belgiu, M.; Grillmayer, R. ON A 2270: 2010-von Profil. AT zur ÖNORM und der Validierung in einem GDI-Verbund. In Angewandte Geoinformatik AGIT 2010; Strobl, J., Blaschke, T., Griesebner, G., Eds.; Wichmann Verlag: Heidelberg, Germany, 2010; pp. 125-130.

65. Bazilian, M.; Rice, A.; Rotich, J.; Howells, M.; DeCarolis, J.; Macmillan, S.; Liebreich, M. Open source software and crowdsourcing for energy analysis. Energy Policy 2012, 49, 149-153.

66. Zoellik, R.B. Opening Remarks: Opening Press Conference Spring Meetings. Available online: http://web.worldbank.org (accessed on 18 February 2014).

67. Janssen, M.; Charalabidis, Y.; Zuiderwijk, A. Benefits, adoption barriers and myths of open data and open government. Inf. Syst. Manag. 2012, 29, 258-268.

68. Auer, S.; Bizer, C.; Kobilarov, G.; Lehmann, J.; Cyganiak, R.; Ives, Z. Dbpedia: A Nucleus for A Web of Open Data. In The Semantic Web; Springer: Berlin, Germany, 2007; pp. 722-735.

69. Streeter, L.A.; Kraut, R.E.; Lucas, H.C., Jr.; Caby, L. How open data networks influence business performance and market structure. Commun. ACM 1996, 39, 62-73.

70. U.S. General Services Administration. The Home of the U.S. Government's Open Data. Available online: http://www.data.gov (accessed on 12 February 2014). 
71. Government of the United Kingdom. data.gov.uk-Opening Up Government. Available online: http://data.gov.uk (accessed on 20 February 2014).

72. Landesamt für Geoinformation und Landentwicklung Baden-Württemberg. Landesamt für Geoinformation und Landentwicklung, Open Data. Available online: https://www.lgl-bw.de/ lgl-internet/opencms/de/07_Produkte_und_Dienstleistungen/Open_Data_Initiative (accessed on 12 February 2014).

73. STATISTIK AUSTRIA. Statistik Austria open.data. Available online: http://data.statistik.gv.at (accessed on 18 February 2014).

74. The City of New York. NYC Open Data. Available online: https://data.ny.gov (accessed on 22 February 2014).

75. Orszag, P. Open Government Directive: Memorandum for the Heads of Executive Departments and Agencies; Executive Office of the President: Washington, DC, USA, 2009.

76. Open Energy Information. Energy Information, Data, and Other Resources, OpenEI. Available online: http://en.openei.org (accessed on 22 February 2014).

77. GISOPT Consortium. Research Project: Structural Optimisation of Storage Facilities. Available online: http://www.geog.uni-heidelberg.de/forschung/gis_energystorage_en.html (accessed on 28 October 2013).

78. O’Donnell, J.; See, R.; Rose, C.; Maile, T.; Bazjanac, V. SIMMODEL: A Domain Data Model for Whole Building Energy Simulation. In Proceedings of the Building Simulation 2011, 12th Conference of International Building Performance Simulation Association, Sydney, NSW, Australia, 14-16 November 2011.

79. Goodchild, M.F. Twenty years of progress: GIScience in 2010. J. Spat. Inf. Sci. 2014, 1, 3-20.

80. European Parliament and the Council. Directive 2007/2/EC of the European Parliament and of the Council of 14 March 2007 Establishing an Infrastructure for Spatial Information in the European Community (INSPIRE). Available online: http://inspire.jrc.ec.europa.eu (accessed on 15 October 2013).

81. Goodchild, M.F. Citizens as sensors: The world of volunteered geography. GeoJournal 2007, 69, 211-221.

82. Resch, B. People as Sensors and Collective Sensing - Contextual Observations Complementing Geo-Sensor Network Measurements. In Advances in Location-Based Services, Krisp, J., Ed.; Springer: Berlin, Germany, 2013; pp. 391-406.

83. OpenStreetMap Community. OpenStreetMap. Available online: http://www.openstreetmap.org (accessed on 24 February 2014).

84. Fan, H.; Zipf, A.; Fu, Q.; Neis, P. Quality assessment for building footprints data on OpenStreetMap. Int. J. Geogr. Inf. Sci. 2014, 28, 700-719.

85. European Parliament and the Council. Directive 2012/27/EU of the European Parliament and of the Council of 25 October 2012 on energy efficiency, amending Directives 2009/125/EC and 2010/30/EU and repealing Directives 2004/8/EC and 2006/32/EC. Available online: http://ec.europa.eu (accessed on 24 February 2014).

86. Brücher, W. Energiegeographie-Wechselwirkungen Zwischen Ressourcen, Raum und Politik; Borntraeger: Berlin/Stuttgart, Germany, 2009. 
87. Schnelle, K.; Voigt, M. Energiewende und Bürgerbeteiligung: Öffentliche Akzeptanz von Infrastrukturprojekten am Beispiel der, Thüringer Strombrücke; Heinrich-Böll-Stiftung: Thüringen, Germany, 2012.

88. Devine-Wright, P. Renewable Energy and the Public: From NIMBY to Participation; Earthscan: London, UK, 2011.

89. Manfren, M.; Caputo, P.; Costa, G. Paradigm shift in urban energy systems through distributed generation: Methods and models. Appl. Energy 2011, 88, 1032-1048.

90. Kropp, C. GIS-Gestützte Online-Bürgerbeteiligung im Kontext der Planung und Genehmigung von Energieinfrastrukturvorhabe: Eine Anforderungsanalyse. Master Thesis, Heidelberg University, Heidelberg, Germany, December 2013.

91. McKenna, E.; Richardson, I.; Thomson, M. Smart meter data: Balancing consumer privacy concerns with legitimate applications. Energy Policy 2012, 41, 807-814.

92. McDaniel, P.; McLaughlin, S. Security and privacy challenges in the smart grid. IEEE Secur. Priv. 2009, 7, 75-77.

93. Bohli, J.M.; Sorge, C.; Ugus, O. A Privacy Model for Smart Metering. In Proceedings of the IEEE International Conference on Communications Workshops (ICC) 2010, Capetown, South Africa, 23-27 May 2010; pp. 1-5.

94. Efthymiou, C.; Kalogridis, G. Smart Grid Privacy via Anonymization Of Smart Metering Data. In Proceedings of the First IEEE International Conference on Smart Grid Communications (SmartGridComm) 2010, Gaithersburg, MD, USA, 4-6 October 2010; pp. 238-243.

95. Krüger, T.; Kolbe, T.H. Building Analysis for Urban Energy Planning Using Key Indicators on Virtual 3D City Models - The Energy Atlas of Berlin. In Proceedings of XXII ISPRS Congress, Melbourne, Australia, 25 August-1 September 2012; doi:10.5194/isprsarchives-XXXIX-B2-145-2012.

96. El-Mekawy, M.; Östman, A.; Hijazi, I. A unified building model for 3D urban GIS. ISPRS Int. J. Geo-Inf. 2012, 1, 120-145.

97. Hijazi, I. Assessing façade visibility in 3D city models for city marketing. ISPRS Int. Arch. Photogramm. Remote Sens. Spat. Inf. Sci. 2013, doi:10.5194/isprsarchives-XL-2-W2-1-2013.

98. Strzalka, A.; Bogdahn, J.; Coors, V.; Eicker, U. 3D city modeling for urban scale heating energy demand forecasting. HVAC\&R Res. 2011, 17, 526-539.

99. Strømann-Andersen, J.; Sattrup, P.A. The urban canyon and building energy use: Urban density versus daylight and passive solar gains. Energy Build. 2011, 43, 2011-2020.

100. Saber, H.H.; Maref, W.; Elmahdy, H.; Swinton, M.C.; Glazer, R. 3D heat and air transport model for predicting the thermal resistances of insulated wall assemblies. J. Build. Perform. Simul. 2012, 5, 75-91.

101. Jung, Y.; Joo, M. Building information modelling (BIM) framework for practical implementation. Autom. Constr. 2011, 20, 126-133.

102. Jochem, A.; Höfle, B.; Rutzinger, M. Extraction of vertical walls from mobile laser scanning data for solar potential assessment. Remote Sens. 2011, 3, 650-667.

103. Byun, S.J.; Yong Byun, S.; Lee, J.; Wan Kim, J.; Sung Lee, T.; Mok Kim, W.; Kyu Park, Y.; Cho, K. An optical simulation algorithm based on ray tracing technique for light absorption in thin film solar cells. Sol. Energy Mater. Sol. Cells 2011, 95, 408-411. 
104. Carrión, D.; Lorenz, A.; Kolbe, T.H. Estimation of the energetic rehabilitation state of buildings for the city of Berlin using a 3D city model represented in CityGML. Int. Arch. Photogramm. Remote Sens. Spat. Inf. Sci. 2010, 38, 31-35.

105. Becker, T.; Nagel, C.; Kolbe, T.H. Semantic 3D Modeling of Multi-Utility Networks in Cities for Analysis and 3D Visualization. In Progress and New Trends in 3D Geoinformation Sciences; Springer: Berlin Heidelberg, Germany, 2013; pp. 41-62.

106. Irizarry, J.; Karan, E.P.; Jalaei, F. Integrating BIM and GIS to improve the visual monitoring of construction supply chain management. Autom. Constr. 2013, 31, 241-254.

107. Koračin, D.; Belu, R.; Canadillas, B.; Horvath, K.; Vellore, R.; Smith, C.; Jiang, J.; Mccord, T. A review of challenges in assessment and forecasting of wind energy resources. Hrvat. Meteorološki Cas. 2011, 47, 13-33.

108. Lopes, J.A.P.; Hatziargyriou, N.; Mutale, J.; Djapic, P.; Jenkins, N. Integrating distributed generation into electric power systems: A review of drivers, challenges and opportunities. Electr. Power Syst. Res. 2007, 77, 1189-1203.

109. Dondi, P.; Bayoumi, D.; Haederli, C.; Julian, D.; Suter, M. Network integration of distributed power generation. J. Power Sources 2002, 106, 1-9.

110. Resch, B.; Blaschke, T.; Mittlboeck, M. Live geography-Interoperable geo-sensor webs facilitating the vision of digital earth. Int. J. Adv. Netw. Serv. 2010, 3, 323-332.

111. Resch, B.; Zipf, A.; Breuss-Schneeweis, P.; Beinat, E.; Boher, M. Towards the live City—Paving the way to real-time urbanism. Int. J. Adv. Intell. Syst. 2012, 5, 470-482.

112. Hiremath, R.B.; Shikha, S.; Ravindranath, N.H. Decentralized energy planning, modeling and application-A review. Renew. Sustain. Energy Rev. 2007, 11, 729-752.

113. Mavrogianni, A.; Davies, M.; Kolokotroni, M.; Hamilton, I. A GIS-based Bottom-Up Space Heating Demand Model of the London Domestic Stock. In Proceedings of the 11th International IBPSA Conference: Building Simulation, Glasgow, Scotland, UK, 27-30 July 2009.

114. Ramachandra, T.V.; Shruthi, B.V. Wind energy potential mapping in Karnataka, India, using GIS. Energy Convers. Manag. 2005, 46, 1561-1578.

115. Keirstead, J.; Jennings, M.; Sivakumar, A. A review of urban energy system models: Approaches, challenges and opportunities. Renew. Sustain. Energy Rev. 2012, 16, 3847-3866.

116. Möller, B.; Lund, H. Conversion of individual natural gas to district heating: Geographical studies of supply costs and consequences for the Danish Energy System. Appl. Energy 2010, 87, 1846-1857.

117. Safirova, E.; Houde, S.; Harrington, W. Spatial Development and Energy Consumption; Resources for the Future: Washington, DC, USA, 2007.

118. San Francisco Department of the Environment, CH2M HILL. San Francisco Energy Map-A Map of Clean Energy Activity Around the City. Available online: http://sfenergymap.org (accessed on 24 February 2014).

119. Solar Essence. Solar Installations Map. Available online: http://www.solaressence.co.uk (accessed on 21 February 2014).

120. National Renewable Energy Laboratory. The Open PV Project. Available online: https://openpv.nrel.gov (accessed on 24 February 2014). 
121. KliBA. Erneuerbare Energien vor Ort (Umweltministerium). Available online: http://www.bw-co2.de (accessed on 24 February 2014).

122. Schulte, C.; Coors, V.; Eicker, U. 3D-Stadtmodelle als Grundlage für Wärmebedarfssimulationen. In GeoForum MV 2012-GIS Schafft Energie: Beiträge der Geoinformationswirtschaft zur Energiewende; Flach, R., Klammer, G., Lerche, U., Bill, T., Eds.; GITO mbH Verlag: Berlin, Deutschland, 2012; pp. 53-62.

123. Loga, T.; Diefenbach, N.; Born, R. Deutsche Gebäudetypologie, Beispielhafte Maßnahmen zur Verbesserung der Energieeffizienz von typischen Wohngebäuden; Institut Wohnen und Umwelt (IWU): Darmstadt, Germany, 2011.

124. DIN. Energieeffizienz von Gebäuden-Berechnung des Energiebedarfs für Heizung und Kühlung (ISO 13790:2008); Beuth Verlag GmbH: Brussels, Belgium, 2008.

125. Rouvel, L. Thermische Gebäudesimulation, Berechnungsverfahren zum Instationären Thermischen Gebäudeverhalten; Rouvel: Munich, Germany, 2010.

126. Jordan, U.; Vajen, K. DHWcalc: Program to Generate Domestic Hot Water Profiles with Statistical Means for User Defined Conditions. In Proceedings of the ISES Solar World Congress, Orlando, FL, USA, 8-12 August 2005.

127. Jordan, U.; Vajen, K. Realistic Domestic Hot-water Profiles in Different Time Scales; Report for IEA-SHC Task, 26; University of Marburg: Marburg, Germany, 2001.

128. Fazlollahi, S.; Mandel, P.; Becker, G.; Maréchal, F. Methods for multi-objective investment and operating optimization of complex energy systems. Energy 2012, 45, 12-22.

129. Verda, V.; Colella, F. Primary energy savings through thermal storage in district heating networks. Energy 2011, 36, 4278-4286.

130. Streckiene, G.; Martinaitis, V.; Andersen, A.N.; Katz, J. Feasibility of CHP-plants with thermal stores in the German spot market. Appl. Energy 2009, 86, 2308-2316.

131. Christidis, A.; Koch, C.; Pottel, L.; Tsatsaronis, G. The contribution of heat storage to the profitable operation of combined heat and power plants in liberalized electricity markets. Energy 2012, 41, 75-82.

132. Horenkamp, W.; Hube, W. VDE-Studie Dezentrale Energieversorgung 2020; Energietechnische Gesellschaft im VDE (ETG): Frankfurt, Germany, 2007.

133. Hollinger, R.; Wille-Hausmann, B.; Wittwer, C. Speicherstudie2013, Kurzgutachten zur Abschätzung und Einordnung Energiewirtschaftlicher, Ökonomischer und Anderer Effekte bei Förderung von Objektgebunden Elektrochemischen Speichern, in Zusammenfassung der Wichtigsten Ergebnisse; Fraunhofer ISE: Freiburg, Germany, 2013.

134. Wille-Hausmann, B. Einsatz der Symbolischen Modellreduktion zur Untersuchung der Betriebsfuehrung im Smart Grid; FernUniversitaet Hagen: Hagen, Germany, 2011.

135. Hauer, A.; Specht, M.; Sterner, M. Energiespeicher Steigerung der Energieeffizienz und Integration Erneuerbarer Energien; Renewable Energy Research Association-FVEE: Berlin, Germany, 2010.

136. Nakata, T. Energy-economic models and the environment. Prog. Energy Combust. Sci. 2004, 30, 417-475.

137. Palzer, A.; Henning, H.M. A future German energy system with a dominating contribution from renewable energies: A holistic model based on hourly simulation. Energy Technol. 2014, 2, 13-28. 
138. Lund, H.; Andersen, A.N. Optimal designs of small CHP plants in a market with fluctuating electricity prices. Energy Convers. Manag. 2005, 46, 893-904.

139. Dobos, L.; Abonyi, J. Controller tuning of district heating networks using experiment design techniques. Energy 2011, 36, 4633-4639.

140. Rolfsman, B. Combined heat-and-power plants and district heating in a deregulated electricity market. Appl. Energy 2004, 78, 37-52.

141. Winkelmüller, S. Optimierung der Nachfrage- und Erzeugungsstruktur Kommunaler Energiesysteme am Beispiel von Wien; Universität Augsburg: Augsburg, Germany, 2006.

142. Molyneaux, A.; Leyland, G.; Favrat, D. Environomic multi-objective optimisation of a district heating network considering centralized and decentralized heat pumps. Energy 2010, 35, 751-758.

143. Casisi, M.; Pinamonti, P.; Reini, M. Optimal lay-out and operation of combined heat \& power (CHP) distributed generation systems. Energy 2009, 34, 2175-2183.

144. Nuytten, T.; Claessens, B.; Paredis, K.; van Bael, J.; Six, D. Flexibility of a combined heat and power system with thermal energy storage for district heating. Appl. Energy 2013, 104, 583-591.

145. Weber, C.I. Multi-objective Design and Optimization of District Energy Systems Including Polygeneration Energy Conversion Technologies; École Polytechnique Fédérale de Lausanne: Lausanne, Switzerland, 2008.

146. Söderman, J.; Pettersson, F. Structural and operational optimisation of distributed energy systems. Appl. Therm. Eng. 2006, 26, 1400-1408.

147. Söderman, J. Optimisation of structure and operation of district cooling networks in urban regions. Appl. Therm. Eng. 2007, 27, 2665-2676.

148. Möller, B. A Danish Heat Atlas for Supply Strategies and Demand Side Management. In Proceedings of the 13th International Symposium on District Heating and Cooling, Copenhagen, Denmark, 3-4 September 2012.

149. Girardin, L.; Marechal, F.; Dubuis, M.; Calame-Darbellay, N.; Favrat, D. EnerGIS: A geographical information based system for the evaluation of integrated energy conversion systems in urban areas. Energy 2010, 35, 830-840.

150. Appelrath, H.-J.; Terzidis, O.; Weinhardt, C. Internet of energy-ICT as a key technology for the energy system of the future. Bus. Inf. Syst. Eng. 2012, 4, 1-2.

151. Palzer, A.; Henning, H.M. A comprehensive model for the German electricity and heat sector in a future energy system with a dominant contribution from renewable energy technologies-Part II: Results. Renew. Sustain. Energy Rev. 2014, 30, 1019-1034.

(C) 2014 by the authors; licensee MDPI, Basel, Switzerland. This article is an open access article distributed under the terms and conditions of the Creative Commons Attribution license (http://creativecommons.org/licenses/by/3.0/). 